\title{
CHARGE CARRIER TRANSPORT IN ZnO/CdS/CdTe/(Cu)/Ni
}

\section{HETEROJUNCTIONS}

Corneliu Rotaru ${ }^{1}$, Sergiu Vatavu ${ }^{1}$, Vladimir Fedorov ${ }^{1}$, Michael Kirsch ${ }^{2}$, Petru Chetruş ${ }^{1}$, Petru Gaşin ${ }^{1}$, Martha Ch. Lux-Steiner ${ }^{2}$ and Marin Rusu ${ }^{1,2}$

${ }^{1}$ Faculty of Physics and Engineering, Moldova State University, 60 A. Mateevici str., MD-2009 Chisinau, Republic of Moldova

${ }^{2}$ Institut für Heterogene Materialsysteme, Helmholtz-Zentrum Berlin für Materialien und Energie, Lise-Meitner-Campus, Hahn-Meitner-Platz 1, 14109 Berlin, Germany

\section{$\underline{\text { Abstract }}$}

Charge carrier transport mechanism in the CdS/CdTe heterojunction with a zinc oxide front contact of a $\mathrm{ZnO}: \mathrm{Al} / \mathrm{i}-\mathrm{ZnO} / \mathrm{CdS} / \mathrm{CdTe} / \mathrm{Cu} / \mathrm{Ni}$ structure has been investigated in the temperature range of $100-373 \mathrm{~K}$. It has been found that at forward biases the charge carrier transport mechanism is determined by tunneling through charge states related to dislocations. An estimation of the concentration of dislocations gives a value of $2.9 \cdot 10^{2} \mathrm{~cm}^{-2}$.

At reverse biases higher than $0.7 \mathrm{~V}$, the charge transport mechanism is determined by tunneling processes. The leakage current component is predominant for reverse voltages lower than $0.4 \mathrm{~V}$.

\section{$\underline{\text { Keywords }}$}

Solar cells, CdS, CdTe, heterojunction, charge transport mechanism 


\section{Introduction}

Being known for a long time as a highly perspective material for solar energy conversion, cadmium telluride (CdTe) [1] and related heterojunctions still remain currently in the focus of research for highly efficient photovoltaic (PV) devices [2]. Among aspects that can advance the research in the field of CdTe based photovoltaics, one can mention the choice of an appropriate transparent conductive oxide (TCO). $\mathrm{ZnO}$ is one of the most appropriate TCO candidates for these purposes. The PV parameters of the solar cells prepared so far with $\mathrm{ZnO}$ layers could be considered as promising [3]. An efficiency of $14 \%$ was achieved for $\mathrm{CdS} / \mathrm{CdTe}$ solar cells with an $\mathrm{Al}$ doped $\mathrm{ZnO}$ ( $\mathrm{ZnO}: \mathrm{Al})$ front contact [4]. One of the challenging issues for devices based on CdTe is the control of the charge carrier transport mechanism through the heterojunction.

This paper presents an analysis of current flow mechanism in a $\mathrm{ZnO}: \mathrm{Al} / \mathrm{i}$ $\mathrm{ZnO} / \mathrm{CdS} / \mathrm{CdTe}$ photovoltaic device at different temperatures.

\section{Experimental details}

$\mathrm{CdS}$ deposited either onto $\mathrm{ZnO}: \mathrm{Al}$ or onto $\mathrm{i}-\mathrm{ZnO}: \mathrm{Al} / \mathrm{ZnO}: \mathrm{Al}$ bilayers by hotwall deposition or by close spaced sublimation have been used as substrates for the deposition of CdTe absorber to complete the $\mathrm{ZnO} / \mathrm{CdS} / \mathrm{CdTe}$ solar cell device structure. Two types of TCO have been used for device manufacturing. The type I TCO consisted of a RF sputtered bilayer structure formed by a $90-\mathrm{nm}$ thick intrinsic $\mathrm{i}-\mathrm{ZnO}$ and by a 400-nm thick highly Al-doped $\mathrm{ZnO}$ (ZnO:Al). Type II TCO consisted of a single layer of a highly $\mathrm{Al}$ doped $\mathrm{ZnO}$ (400-500 nm thick) only. The optical transmission of $\mathrm{ZnO}: \mathrm{Al}$ layers in the visible wavelength range was $\sim 85 \%$.

The CdS and CdTe deposition processes and equipment have been presented in Ref 5. The analysis of the deposition parameters (especially of the substrate temperature) allowed to determine the optimum substrate temperatures as follows: 320 - 
$450^{\circ} \mathrm{C}$ for the $\mathrm{CdS}$ deposition and $370-450^{\circ} \mathrm{C}$ for the CdTe deposition. The optimum evaporation source temperatures were determined elsewhere [5]. The combination of the optimum substrate and source temperatures allowed to prepare best efficient solar cell devices.

CdTe deposition has been followed by a conventional for this material annealing in the presence of $\mathrm{CdCl}_{2}$ [6] at $390-410^{\circ} \mathrm{C}$. Br-methanol etching has been used before back contact deposition. $\mathrm{Cu}(4 \mathrm{~nm})$ and $\mathrm{Ni}(120 \mathrm{~nm})$ have been successively deposited onto CdTe as back contacts.

The PV parameters of the investigated $\mathrm{ZnO}: \mathrm{Al} / \mathrm{i}-\mathrm{ZnO} / \mathrm{CdS} / \mathrm{CdTe} / \mathrm{Cu} / \mathrm{Ni}$ solar cells are: short-circuit current $J_{\mathrm{sc}}=17.46 \mathrm{~mA} / \mathrm{cm}^{2}$, open circuit voltage $U_{\mathrm{oc}}=0.70$, fill factor $\mathrm{ff}=0.49$ and efficiency $\eta=6.00 \%$ under AM1.5 $\left(100 \mathrm{~mW} / \mathrm{cm}^{2}, 25^{\circ} \mathrm{C}\right)$ conditions.

The current-voltage dependencies of $\mathrm{ZnO}: \mathrm{Al} / \mathrm{i}-\mathrm{ZnO} / \mathrm{CdS} / \mathrm{CdTe} / \mathrm{Cu} / \mathrm{Ni}$ structures have been studied by using the Keithley 4200 SCS system equipped with Keithley 4200-PA PreAmp. The heterojunctions area for the analyzed samples varied from 0.5 $\mathrm{cm}^{2}$ to $1.0 \mathrm{~cm}^{2}$.

\section{Results and discussion}

The perceptiveness of the $\mathrm{ZnO}: \mathrm{Al}$ used in this work as TCO has been confirmed by the analysis of the external quantum efficiency plot in Fig. 1. An extension of spectral response in the 350-500 $\mathrm{nm}$ spectral region became possible while using both $\mathrm{ZnO}: \mathrm{Al}$ and $\mathrm{i}-\mathrm{ZnO} / \mathrm{ZnO}: \mathrm{Al} \mathrm{TCO}$ as front contacts in combination with $\mathrm{CdS}$ thin films of reduced thicknesses.

The current-voltage dependencies have been studied in the temperature range of 100-373K and under various illumination conditions. The I-U plots show highly asymmetric diode-type curves. The rectifying coefficient is $10^{3}-10^{4}$ at $1 \mathrm{~V}$. The charge current flow mechanism is temperature dependent. Due to the fact that the CdS/CdTe 
heterojunctions with type I and type II TCO have shown similar charge carrier transport mechanism, a detailed analysis will be given for heterojunction with type I TCO only.

3.1 Forward bias As one can see from Fig. 2, the current voltage dependencies contain two slopes: the slope I between 0.1 and $0.4 \mathrm{~V}$ and the slope II between 0.5 and $0.75 \mathrm{~V}$ (the heterojunction area for the analyzed samples was $0.5 \mathrm{~cm}^{2}$ ). The built-in potential has a linear temperature dependence, its tangent being equal to $2.52 \cdot 10^{-3} \mathrm{~V} / \mathrm{K}$. The analysis of the forward current and of the saturation current temperature dependence clearly suggested that the most probable charge carrier transport mechanism is determined by tunneling processes. As one can see from Fig. 3, there are two slopes in the direct current temperature dependence for each bias. One can notice that the slopes' intersection is shifting towards higher temperatures as the bias drops down to $0.2 \mathrm{~V}$. These observations could be explained by considering that at high temperatures the tunneling mechanism is assisted by an additional one. A general analytical formula for the I-U plot can be presented as:

$$
I_{\mathrm{f}}=I_{0} \exp (B T) \exp (A U)
$$

However, in order to achieve an appropriate fit of the experimental data, a model which has been previously applied for the evaluation of the $\mathrm{SnO}_{2} / \mathrm{CdS} / \mathrm{CdTe}$ heterojunction [7] will be used for the analysis of the $\mathrm{ZnO}: \mathrm{Al} / \mathrm{CdS} / \mathrm{CdTe}$ heterojunction investigated in this work. The theory and the model for tunneling in heterojunctions have been described thoroughly in Refs. 8 and 9. The model considers that tunneling takes place through dislocations which are present in the space charge region. The forward current is given as: 


$$
I_{\mathrm{f}}=I_{s}\left(\exp \left(\frac{e U}{\varepsilon}\right)-1\right)
$$

where $\varepsilon$ - is the characteristic energy. One can underline that in the $\varepsilon$ vs. T dependence three slopes are present and it is a linear one with a tangent of $-0.2 \cdot 10^{-3} \mathrm{eV} / \mathrm{K}$ for the temperature interval of $230-300 \mathrm{~K}$ and extrapolation of $\varepsilon$ to $\mathrm{T}=0 \mathrm{~K}$ gives a value of $\varepsilon=830 \mathrm{meV}$. The latter value is several times larger than the one reported for $\mathrm{CdS} / \mathrm{CdTe}$ heterojunction deposited on $\mathrm{SnO}_{2}$. For temperatures up to $373 \mathrm{~K}$ the $\varepsilon_{0}=150$ meV. It is considered that the tunneling processes through different defects (dislocations) are taking place at different temperatures (defect activeness varies at different temperatures). The concentration of dislocations can be estimated by using respective formulas from the Ref. 8 . For the analyzed samples a value of $2.9 \cdot 10^{2} \mathrm{~cm}^{-2}$ has been determined.

3.2 $\quad$ Reverse bias The I-U temperature dependence at reverse biases in double logarithmic scale is given in Fig. 4. The dependence can be approximated by a power function with an exponent $m_{i}$ where $i$ is the slope number. One can observe basically two slopes for each temperature. The first one is related to the interval of $0.05-$ $0.4 \mathrm{~V}$, where the $m$ values vary between $0.79(368 \mathrm{~K})$ and $1.3(188 \mathrm{~K})$. It is considered that for this voltage range the leakage currents dominate. For the reverse biases between $0.75 \mathrm{~V}$ and $1.6 \mathrm{~V}$ the $m$ parameter reaches 1.86 . For the voltage interval of $0.75-1.6 \mathrm{~V}$ the reverse current temperature dependence at fixed bias was analyzed. As one can see from Fig. 5 in this case the charge carrier transport might be of tunneling origin (considering current vs. T dependence and I-U is an exponential function). A previously described model in Ref. 10 has been used to analytically calculate the number of tunneling steps and a concentration of defects as it is given in formula 3. 


$$
\ln \frac{I_{r e v}}{U}=-\Theta\left(E_{g p}+\Delta E_{v}\right) \sqrt{\frac{E_{r}}{U_{D}-U}}
$$

where: the $\Theta$ - is the number of tunneling steps, $E_{r}$ - is the barrier height corresponding to one tunneling step. The $\ln \frac{I_{\text {rev }}}{U}=f\left(\frac{1}{\sqrt{U_{D}-U}}\right)$ plot allows a direct $\Theta$ calculation at different T (Fig. 6).

The concentration of traps $N_{t}$ involved in the tunneling processes (Table 1) is given in [10] by formula:

$$
\frac{I}{U} \exp \left(\gamma\left[U_{D}-U\right]^{-1 / 2}\right)=a e^{2} \frac{N_{t}}{h}
$$

where: $a$ - is the lattice constant, $h$ - Planck's constant, $U_{D}$ - built-in voltage.

\section{Concluding remarks}

In summary, differences between current transport mechanisms in solar cell devices prepared with various TCOs at different substrate temperatures have been investigated. The analysis of the charge transport mechanism shows that the use of $\mathrm{ZnO}$ window layers for the preparation of $\mathrm{CdS} / \mathrm{CdTe}$ solar cells results in the formation of device structures with reduced concentration of dislocation related defects. The concentration of the latter defects is by three orders of magnitude lower when compared to previously published results on devices with $\mathrm{SnO}_{2} / \mathrm{CdS} / \mathrm{CdTe}$ heterostructures [7]. The estimated concentration of traps amounts to $2.9 \cdot 10^{2} \mathrm{~cm}^{-2}$.

\section{$\underline{\text { Acknowledgements }}$}


This work was supported by bilateral Moldova-Germany ASM/BMBF grant MDA 09/023 and 10.820.05.03GA. Corneliu Rotaru would like to acknowledge institutional grant 11.817.05.12A and NITECH SRL (Republic of Moldova) and personally Dr. Catalin Grosu for sponsoring his participation at EMRS Spring Meeting 2012. 


\section{$\underline{\text { References }}$}

[1] J. Britt, C. Ferekides, Appl. Phys. Lett. 62 (1993) 2851.

[2] X. Wu, J.C. Keane, R.G. Dhere, C. DeHart, D.S. Albin, A. Duda, T.A. Gessert, S. Asher, D.H. Levi, P. Sheldon, $17^{\text {th }}$ European Photovoltaic Solar Energy Conference, Munich, Germany, 22-26 October 2001, Proceedings, (2001) 995.

[3] R. G. Dhere, M. Bonnet-Eymard, E. Charlet, E. Peter, J. N. Duenow, Jia V. Li, D. Kuciauskas, T. A. Gessert, Thin Solid Films 519 (2011) 7142.

[4] A. Gupta, A. D. Compaan, Appl. Phys. Lett. 85 (2004) 684.

[5] S. Vatavu, C. Rotaru, V. Fedorov, M. Rusu, T Stein, M. Caraman, Ig. Evtodiev, C. Kelch, M. Kirsch, M. Ch. Lux-Steiner, P. Chetruş, P. Gaşin, Thin Solid Films in press (E-MRS-2012 Spring Meeting special issue).

[6] J. Luschitz, B. Siepchen, J. Schaffner, K. Lakus-Wollny, G. Haindl, A. Klein, W. Jaegermann, Thin Solid Films 517 (2009) 2125.

[7] S. Vatavu, P. Gaşin, Thin Solid Films 515 (2007) 6179.

[8] V.V. Evstropov, Yu.V. Zhilyaev, M. Dzhumaeva, N. Nazarov, Phys. Tech. Semicond. 31 (1997) 115.

[9] V. V. Evstropov, M. Dzhumaeva, Yu. V. Zhilyaev, N. Nazarov, A. A. Sitnikova, L. M. Fedorov, Semiconductors 34 (2000) 1305.

[10] S.S. Ou, O.M. Stafsudd, B.M. Basol, Solid-State Electron. 27 (1984) 21. 


\section{$\underline{\text { Figure captions }}$}

Figure 1 External quantum efficiency of solar cells prepared on different substrates:

ITO1a - ITO/CdS/CdTe/Metal

$\mathrm{SNO} 5 \mathrm{a}-\mathrm{SnO}_{2} / \mathrm{CdS} / \mathrm{CdTe} / \mathrm{Metal}$

IZALV1a - ZnO:Al/i-ZnO/CdS/CdTe/Metal

ZALHT2a - ZnO:Al/CdS/CdTe/Metal

ZALV9a - ZnO:Al/CdS/CdTe/Metal.

Figure 2 The I-U curves of a Glass/ZnO:Al/i-ZnO/CdS/CdTe/Cu/Ni solar cell measured in the temperature range between $108 \mathrm{~K}$ and $368 \mathrm{~K}$ with the step of $10 \mathrm{~K}$.

Figure 3 The forward current temperature dependence at different biases for a Glass/ZnO:Al/i-ZnO/CdS/CdTe/Cu/Ni solar cell.

Figure 4 The reverse current vs. voltage curves of a $\mathrm{ZnO}: \mathrm{Al} / \mathrm{i}-\mathrm{ZnO} / \mathrm{CdS} / \mathrm{CdTe} / \mathrm{Cu} / \mathrm{Ni}$ solar cell measured at temperatures as in Fig. 2.

Figure 5 Reverse current vs. temperature curves of a Glass/ZnO:Al/i$\mathrm{ZnO} / \mathrm{CdS} / \mathrm{CdTe} / \mathrm{Cu} / \mathrm{Ni}$ solar cell at different voltages.

Figure 6 The plot $\ln \frac{I_{r e v}}{U}=f\left(\frac{1}{\sqrt{U_{D}-U}}\right)$ at selected temperatures for a Glass/ZnO:Al/i$\mathrm{ZnO} / \mathrm{CdS} / \mathrm{CdTe} / \mathrm{Cu} / \mathrm{Ni}$ solar cell. 
Click here to download Figures (if any): Table 1 ROTARU_MQCC7 Revised 2.doc

\section{Table 1}

The concentration of defects (traps) $N_{t}$ and tunneling steps $\Theta$ at different temperatures

\begin{tabular}{ccc}
\hline $\mathrm{T}, \mathrm{K}$ & $N_{t}, 10^{3} \mathrm{~cm}^{-3}$ & $\Theta$ \\
\hline 168 & 1.14 & 95 \\
188 & 0.98 & 85 \\
208 & 0.97 & 80 \\
258 & 0.56 & 58 \\
368 & 20.97 & 18 \\
\hline
\end{tabular}


Figure 1

Click here to download Figures (if any): Figure 1 ROTARU_MQCC7 Revised_MR-1.doc

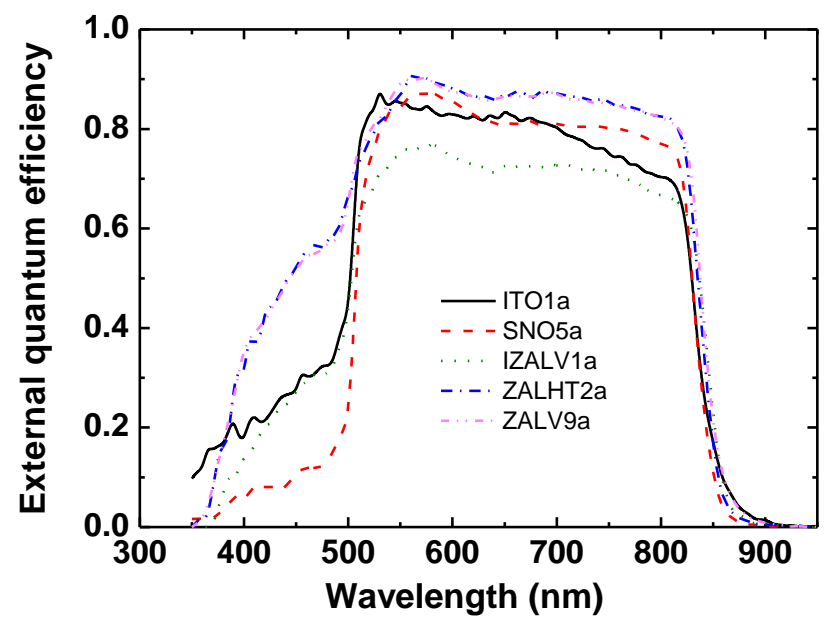

Figure 1 


\section{gure 2}

Click here to download Figures (if any): Figure 2 ROTARU_MQCC7 Revised_MR-1.doc

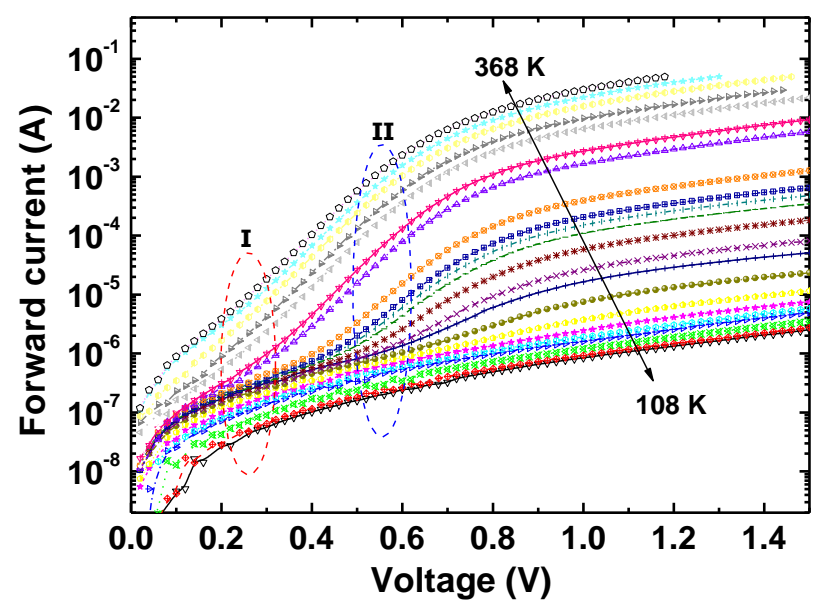

Figure 2 
Figure 3

Click here to download Figures (if any): Figure 3 ROTARU_MQCC7 Revised_MR-1.doc

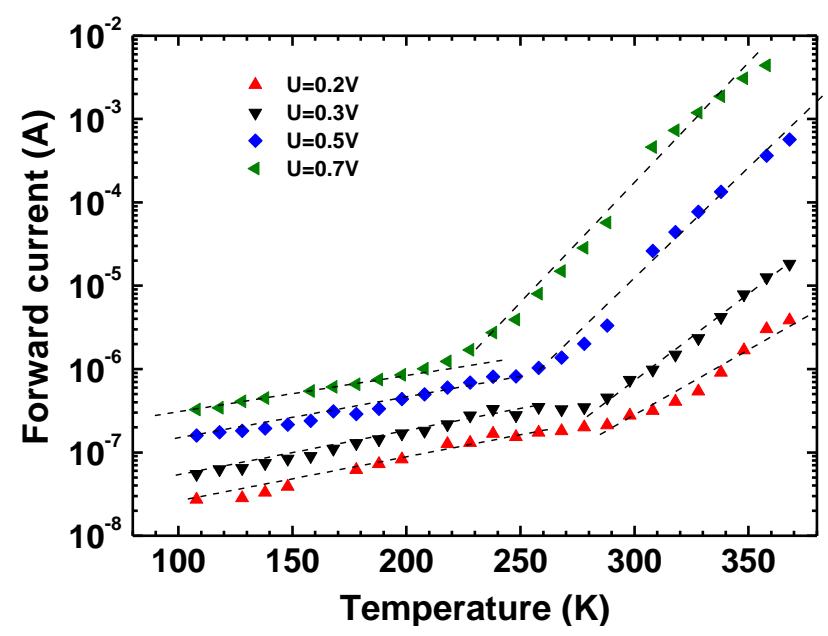

Figure 3 


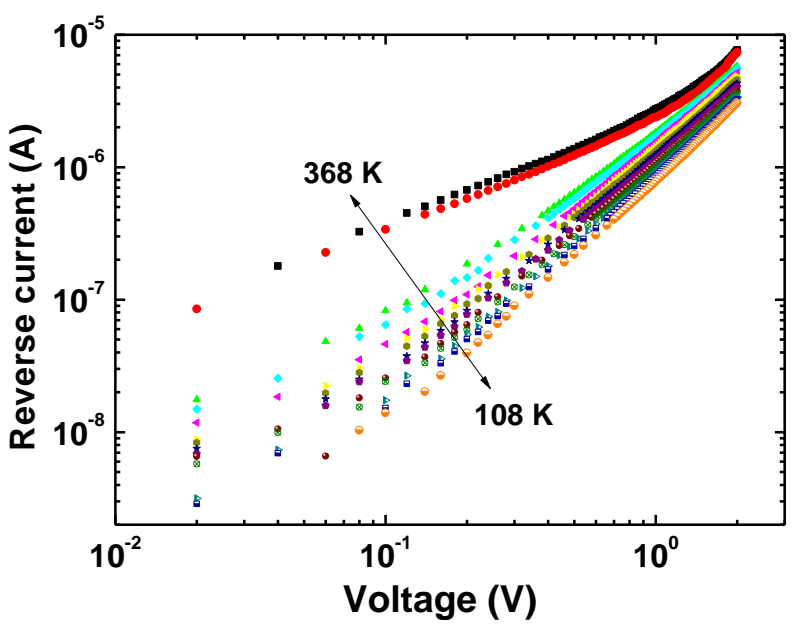

Figure 4 


\section{Figure 5}

Click here to download Figures (if any): Figure 5 ROTARU_MQCC7 Revised_MR-1.doc

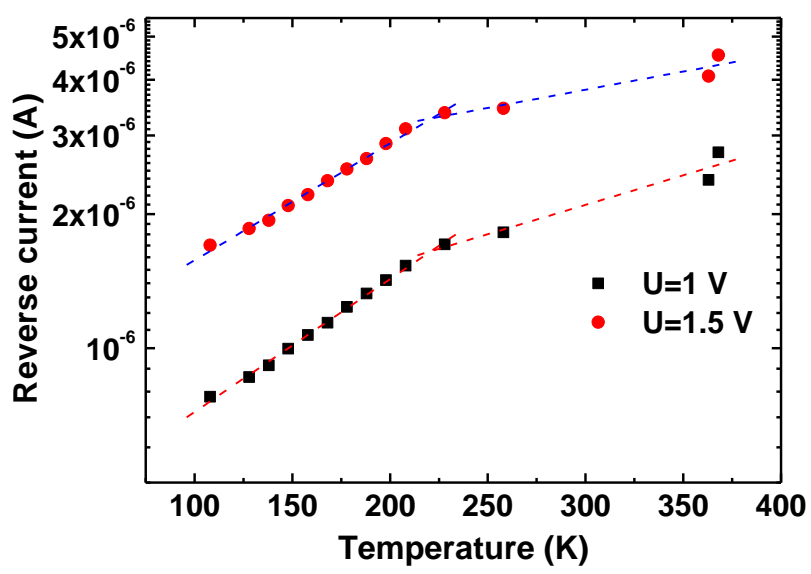

Figure 5 
Figure 6

Click here to download Figures (if any): Figure 6 ROTARU_MQCC7 Revised_MR-1.doc

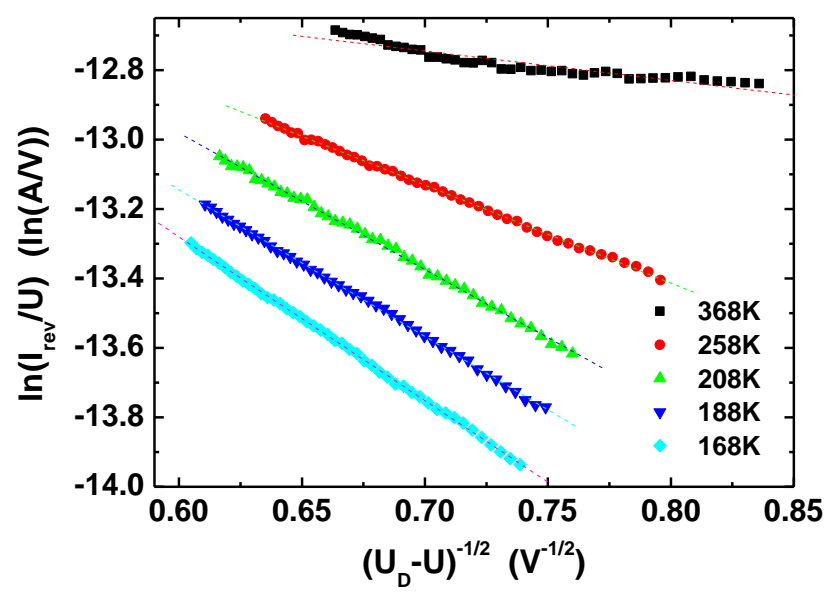

Figure 6 